\title{
How Staff RNs Perceive Nurse Manager Roles
}

\author{
Rebecca A. Feather ${ }^{1}$, Patricia R. Ebright ${ }^{2}$ \\ ${ }^{1}$ School of Nursing, Indiana University, Bloomington, USA \\ ${ }^{2}$ School of Nursing, Indiana University, Indianapolis, USA \\ Email: reafeath@indiana.edu, prebrigh@iupui.edu
}

Received June $11^{\text {th }}, 2013$; revised July $22^{\text {nd }}, 2013$; accepted July $29^{\text {th }}, 2013$

\begin{abstract}
Copyright (c) 2013 Rebecca A. Feather, Patricia R. Ebright. This is an open access article distributed under the Creative Commons Attribution License, which permits unrestricted use, distribution, and reproduction in any medium, provided the original work is properly cited.
\end{abstract}

\begin{abstract}
Purpose: Nurse managers' behaviors and job satisfaction are commonly addressed in the literature; however, registered nurse perceptions of nurse manager behaviors provide a unique perspective that may inform future strategies designed to enhance $\mathrm{RN}$ job satisfaction. The purpose of this study was to assess the perceptions of registered nurses that were explored through focus groups to learn the behaviors of nurse managers that most influence registered nurse's job satisfaction. Methods: Five focus groups were conducted through semi-structured interviews of a total of $28 \mathrm{RNs}$ to provide data that were coded through qualitative content analysis for themes. Findings: The findings provide nurse managers with data related to the perceptions of RNs and the behaviors of managers that influence job satisfaction. In relation to the focus group's discussions, a disconnection was identified between the perceptions of the RNs regarding their actual work issues and the nurse manager's role on the hospital unit. There were five themes that emerged in the category of RNs perceived disconnect between work issues and the manager's role. The daily role, manager meeting time, visibility of nurse managers, no longer a nurse, and RN preferences for the nurse manager role. Conclusion: Findings support past research in relation to the perceptions of RNs wanting to be respected, included in communication, and the need to feel cared for by nurse managers to have higher levels of job satisfaction. This study provided findings important to staff nurses, nurse managers and administration. There is a need for administrator support for nurse manager's ability to spend more time on the unit with RNs to attend to direct care provider relationships and team building through communication with staff is a recommended approach for decreasing the disconnect between RNs and nurse managers.
\end{abstract}

Keywords: Job Satisfaction; Managers’ Behavior; Disconnect

\section{Introduction}

The American Nursing Association (ANA) has recognized that supply solutions for the nursing workforce must focus on both recruitment and retention of registered nurses (ANA, 2008). Because current research shows that job satisfaction may influence the retention of registered nurse (RN) staff in light of the predicted shortage over the next 10 to 15 years, it is important to focus on the determinants of $\mathrm{RN}$ job satisfaction. A study by Gormley (2011) indicated anticipated turnover by RNs was correlated to the work environment and perceptions of nursing management. This article reports on findings of a study to identify RN perceptions of nurse manager behaviors that have been shown to influence RN job satisfaction. Focus group interview responses from RNs demonstrated a disconnection between what RNs saw the manager doing and their own work.

\section{Background}

According to a study by Aiken, Clarke, Sloane, et al. (2001), more than 40 percent of hospital nurses reported lack of satisfaction with their jobs. Nursing and human resource studies have identified the relationship between the nurse manager and the nursing staff as invaluable to nurse job satisfaction. Researchers have reported that nurse managers provide a vital role in influencing the type of work environment that nurses work in daily and, therefore, have an effect on the retention of RNs (Shirey, Ebright, \& McDaniel, 2008).

Staff nurses stated in a study by Aiken et al. (2001) that managers influenced their job satisfaction through behaviors of providing recognition and appreciation, meeting personal needs, helping or guiding them, using leadership skills effectively, meeting unit needs, and supporting the team. Likewise, Herrin and Spears (2007) found a supportive environment to be one of the most important factors associated with job satisfaction for nurses, and nurse managers are important in structuring the type of environment critical to the satisfaction and retention of staff nurses (Force, 2005; Kramer et al., 2007). In additional studies, and consistent with previous evidence about the importance of nurse manager behaviors, staff nurses reported in exit interviews that nurse manager behaviors most influenced their decision to leave their positions (Kramer et al., 2007; Shobbrook \& Fenton, 2002).

The role of the nurse in charge of the patient care unit has changed over the past several decades from being the "head nurse" in the 1980's, who was the expert clinician, to becoming a manager of one or several units in the 1990's. This role involved budgeting, managing or directing patient placement and personnel management (Kramer, Schmalenberg, \& Maguire, 
2008). Currently, the role has expanded even more to include more leadership behaviors such as counseling staff, orienting physicians, and facilitating teamwork on the units. Has the increase in responsibilities of the nurse manager led to a decrease in RN job satisfaction? Has the relationship between the two positions diminished due to the inability of the nurse manager to fulfill the perceived expectations of their nursing staff?

\section{Methods}

Design. We conducted a qualitative descriptive study using focus groups to explore RN perceptions of the behaviors of their nurse managers that influenced their job satisfaction. The data reported in this paper relate to our finding that the RNs seem to have a disconnection between their perceptions of their managers' daily activities and the influence on the RNs' work and health care environment.

Sample. A purposive sample of $28 \mathrm{RNs}$ was recruited from the target population of available RN staff nurses currently employed by two nationally accredited, community-based hospitals in the Midwest, both with a minimum of 50 licensed beds.

A staff nurse was defined as an RN on a hospital unit responsible for the care of a certain number of patients admitted to that unit. Staff nurse inclusion criteria included a minimum of six months of experience in patient care and having a nurse manager who had been employed for a minimum of six months.

The definition of a Nurse Manager was an RN who had 24-hour accountability for the operations of one or more hospital or clinic units, regardless of the title given to that position. This position involved management of charge and staff nurses on all shifts and accountability for those positions. To be eligible for their staff to participate in this study, the nurse manager must have had one or more years of experience as a nurse manager. The required-year experience is important in order to establish that the nurse manager is not in the orientation or initial/transitional stage of learning the role of management. Lack of experience in this position could pose an external threat to the study. Other demographics about the nurse manager were not included to protect the confidentiality of the RN participants.

Both organizations had a charge nurse $(\mathrm{CN})$ role in place on the units who may or may not have taken patients in addition to their $\mathrm{CN}$ responsibilities. The $\mathrm{CN}$ was not included in the definition of being in the role of a nurse manager for the purposes of this study.

Recruitment goals for the sample were met by including staff nurse participants from each of the two organizations in focus groups of five to eight participants, with a minimum of two focus groups per organization. Each focus group represented multiple units and shifts, including at least 5 and no more than 8 participants in the order in which they volunteered. The nurses had varying levels of experience, increasing the likelihood of diverse participants for the identification of common themes related to the influence of nurse manager behaviors on job satisfaction.

Procedures. After obtaining approval from the institutional review board (IRB) from the university and both hospital IRBs, focus groups were established through a recruitment process including email and fliers posted on the nursing units. Focus groups were conducted after regular business hours and at a location away from the clinical unit and nurse manager offices to protect the privacy of the participants. At the beginning of each focus group, participants were asked to complete a onetime demographic questionnaire. After that, the investigator asked participants to respond in their focus group to probing questions regarding nurse manager behaviors that positively or negatively affected the participants' job satisfaction (Figure 1). The focus group process allows for sharing and comparing experiences in relation to the topic that would be less accessible without the group interaction (Morgan, 1998). The probing questions were used to explore issues and generate in-depth responses from the RNs.

All focus group discussions were confidential and audio-recorded for transcription purposes. The evolving pattern of discussion helped to guide probing questions to supplement responses in subsequent groups. The investigator created a transcript from each audio recording, which became the raw data that were subject to analysis (Sandelowski, 1995).

Data Analysis. Transcripts were proofed for accuracy by comparing the audio tapes to the written transcripts. Data were analyzed for each focus group separately. The research team included two qualitative analysis experts, both with knowledge of nursing leadership and management, and one instrument development expert knowledgeable in the aspects of comparison of the data with past and current research results. The research team conducted content analysis of the data and then summarized the information (Sandelowski, 1995).

Content analysis of audio transcripts and repeated iterative discussion among members of the research team resulted in two conceptual categories: manager behaviors supportive of RNs and, the focus of this article, RNs' perceived disconnect between work issues and the manager's role.

\section{Results}

\section{RNs' Perceived Disconnect between Work Issues and the Manager's Role.}

Each of the RNs in the five focus groups were asked to discuss his/her typical day at work and the problems that often occurred on a daily basis. However, initially, very little of the discussions included the nurse manager's role in everyday life on the unit. As the RNs began to describe their daily routine and the problems or issues that often occurred on their unit or with patient care, they did not talk much about their manager being present or having an impact on how the unit functioned on a typical day. There seemed to be a disconnection between the perceptions of the RNs regarding their actual work issues and the nurse manager's role on the hospital unit. The following themes (Figure 2) emerged in the category of RNs perceived disconnect between work issues and the manager's role. Each theme represents a discussion that occurred during a minimum of 3 focus groups (or in over 50 percent of the groups).

The daily role. A disconnect was frequently apparent when RNs explicitly stated that the nurse manager did not play a role

1) Tell me about a really memorable day for you at work, good or bad.
2) What do you think makes a day go well and go poorly for you?
3) What part do you think your manager plays in how your day goes at
work?
4) What might your manager do to worsen your day at work?
5) What might your manager do to improve your day at work?

Figure 1.

Focus group interview questions. 
1) The daily role

2) Manager meeting time

3) Visibility of nurse managers

4) No longer a nurse

5) RN preferences for the nurse manager role

Figure 2.

Themes surrounding the $\mathrm{RN}$ disconnect with the nurse manager role.

in their day-to-day job in providing patient care.

One RN stated: “The only time that she's really involved in what we're doing is when we're full and there are patients that need to be placed and she wants us to constantly call the doctors and get them transferred. That is hard to do when you have critical patients that still need our attention.”

A second RN did not relate the manager to the daily needs of the unit: "Our manager is fantastic, the one we have right now, but as far as my day to day, it does, she doesn't really have an effect on my day."

Manager meeting time. The discussion often targeted the amount of time the nurse managers spent in meetings and how this part of their role kept them from being active participants on the unit to solve problems with patient care or simply to show the staff they were there to support them.

As one RN said: “They're going to come and they're going to come flying to the unit if there's something wrong and they're going to be there for you, which is great, but these meetings I think preclude them being able to help on a daily basis in a way that they might be able to help even more, which would be nice. And I also think by virtue of having all these meetings that it pulls them away from the day-to-day activity of what really happens on a unit sometimes, so that when you're making policy, but you're not there as much, it's harder for you to really see how what you're doing is going to impact that person and that's what scares me about the number of meetings that they have to attend."

Others also shared concerns that meetings hindered managers' effectiveness because "that's basically all they do is just meetings from the time they get here until the time they go home mostly" and "if you're in different meetings all the time, how can you be effective? I don't know." One nurse described her manager as attending "meetings about meetings, exactly" and believed that "they kind of need to be on the floor."

Visibility of nurse managers. Other discussions by nurses who worked nights or weekends also involved a disconnection between the manager's role and the functioning of the unit. A nurse who worked mainly weekends commented that "I never see her on the weekends. When I'm there during the week or before I went weekend option, you would see her Monday through Friday-every morning that she wasn't already in meetings."

One RN described her perception of the role of the nurse manager in comparison to the charge nurse: "I think the charge nurse actually plays a bigger role than your manager. Our manager is there, but if something goes down you're going to go to your charge nurse first, so they are more important. That's just me, not in the step-by-step involvement. With my manager, only if something major goes wrong do you ever see them.”

No longer a nurse. Finally, one particular perception by the nurses during the focus group discussions highlighted a disconnect between the manager and the actual work of nursing at the bedside. The nurses often shared opinions in relation to the manager no longer knowing how to be a nurse, such as this comment: "She's there. She makes an appearance and she's nice. I've just heard other people, when it's been really busy like, she'll say she'll get them some help and then the help she gives is saying," You're doing a great job," but doesn't jump in and put on a pair of gloves or do anything like that.”

Another nurse shared feelings about how the manager loses the connection with the clinical aspect of the job when taking on the manager role: "They have more administrative things than really nursing things. Likely, they're not held together. The connection is broken, when they step up. I see it being different when you are a clinical nurse and you go one step up. Most of them when they are managers, they are managers, not clinical managers."

The RNs believed the managers were not able to relate to the many problems the nursing staff had on a day-to-day basis, including the physical stress and strain of being directly involved in patient care. One RN commented: "I'd just like some feedback because I feel like my boss has no idea what kind of a job I do because there's a big gap between what she does and what happens on the floor."

Another described a level of frustration when staff perceived the nurse manager as being disconnected from the demands of the job of an RN: "I do wish the managers... could put their self in our shoes sometimes. Because, you know, we do have limits, not only physically but emotionally too. I mean, sometimes at the end of the day when I know when we go home we're just wiped out. We're usually there till 6 , sometimes later. We stay until the patients are done and it can be a long day. It's mentally exhausting as well as physically."

$R N$ preferences for the nurse manager role. Often the discussion led to RNs sharing their expectations of the nurse manager. For example: "Just actually physically being in front of somebody, you know. Listening to report, just so you kind of get a feel for, you know, what the staff's day is going to be. That would be nice. Showing up on the off shifts and just being in that full-time slot and you know, you could set your watch by when she's going to get there and when she's going to go home. Answering their cell phone when staff calls because they need something, and you know, I think we are expected to only call when it's something that's really out of the ordinary."

Yet another nurse described how it affected the staff when the manager did provide assistance during a time when they were short staffed: "Even if, you know, you're short staffed, I mean, you can have a good day when you're short staffed, it just depends on the support that you do get from the people that are there and if your manager can come out and support you while you're having that bad day. It just kind of alleviates that."

\section{Discussion}

Managers as leaders have two broad and independent functions, according to Hersey and Blanchard (1977). One dimension is production or task oriented, and the other is employee oriented with a focus on relationships, building teamwork, and employee identification with the organization. Findings from this study show that the staff nurse participants generally viewed their managers as being task oriented in relation to attending meetings and scheduling staff, for example, but did not perceive their managers to be employee oriented with a focus on relationships, building teamwork, or employee identification with the organization. In this study, the nurses did not usually see a connection between the daily tasks of the manager and the 
manager's role in solving work issues when they occurred during a shift. And yet the nurses seemed to want more connection and communication with the manager. These findings are consistent with a study by Sellgren et al. (2006), who found that, when both subordinates and managers were provided the same survey on leadership behaviors, thesubordinates preferred different leadership behaviors from those that managers thought were appropriate. In another study by Gormley (2011) significant differences were indicated between nurses and the nurse manager's perceptions of the work environment. Managers rated the environment higher than the staff on all subscales. Both of these studies also revealed a disconnection between the perceptions of the nurses and the beliefs of the nurse managers.

A study by Schmalenberg and Kramer (2009) found that if the nurse manager is involved in roles or behaviors that are not perceived by the nurses as part of their job, then the nurse manager is seen as being non-supportive. In a study by Shirey, Ebright and McDaniel (2008) where nurse managers were interviewed about their roles on the unit, they stated the need to spend an adequate amount of time on the unit in order to be aware of and prevent issues from growing into bigger problems. However, unrealistic expectations of their roles by administration (being in meetings, putting out fires, taking on additional responsibilities) may keep them from being present on the unit as much as they would like to be (Shirey, Ebright, \& McDaniel, 2008).

Given the findings of this study, and potential for similar situations in other complex healthcare settings reflected in recent literature on the nurse manager role, stress and work (Shirey, Ebright, \& McDaniel, 2013), staff nurse perceptions of the manager role have important implications for nursing education and service settings. First, staff nurses may not understand the role of the nurse manager and therefore may have unrealistic expectations of their nurse manager. Second, how do we enable nursing management to carry out both the task and leadership functions described by Hersey and Blanchard (1977) that may assist them in fulfilling the perceived expectations of the RN staff? Because supportive roles and behaviors of nurse managers may vary, or be non-existent, among hospitals and patient care units, an extrinsic list of supportive behaviors must be built and validated for comprehensiveness and to diminish the lack of understanding of the nurse manager role by staff nurses (Schmalenberg \& Kramer, 2009).

In a study by Shirey, Ebright and McDaniel (2008) managers expressed that younger nurses often did not find the role of the nurse manager to be desirable, and that they often asked managers "what do you do" and "is it worth it" (p. 128). Managers expressed in the same study that a lack of clarity of their roles creates ambiguity with their position as different people expect different things from the nurse manager (Shirey, Ebright, \& McDaniel, 2008), thus possibly leading to the disconnect that occurs between RN perceptions of the role and the actual role expectations of the nurse manager by hospital administration. The participants in our study indeed did not seem to have an understanding of the roles of management, indicating a need for a dialogue between the nurse manager and the nursing staff to occur so that perceptions and expectations of RNs can be clarified to improve the effective performance of the nurse manager (Schmalenberg \& Kramer, 2009; Utriainen \& Kyngas, 2009).

Very few of the RNs mentioned the manager as their go to person to assist them in solving problems related to staffing, patient care, or negative physician relationships. Findings reflected staff perceptions of managers as out of sight, out of mind and not being there to provide support for patient care or to meet the individual needs of the staff.

The most important implication from these study findings is related to the ability and capacity for nurses in the nurse manager role to carry out functions that capture both leadership dimensions (task and relationships) described by Hersey and Blanchard (1977). The manager who is office bound and has rigid rules with authoritative styles of communication undermines the morale of the staff by increasing feelings of powerlessness, emotional exhaustion and decreased levels of job satisfaction (Stuenkel, Nguyen, \& Cohen, 2007). Are nurse managers working in our current healthcare settings, with their constant change and complexity, realistically able to attend to the dimension of the role that includes being employee oriented with a focus on relationships, building teamwork, and employee identification with the organization?

There is a need for nurse managers to discuss the roles and expectations or perceptions of the RNs with administration as they also affect the support a nurse manager can provide to the nursing staff (Schmalenberg \& Kramer, 2009). Nurse managers describe their jobs being stressful due to the perceived demands of their roles by staff and administration, and not having the time or resources to meet those demands (Shirey, Ebright, \& McDaniel, 2008). Organizations that require participation by nurse managers in meetings and other time spent away from the direct care areas decrease availability of the manager. Lack of presence on the unit affects the ability of the nurse manager to build relationships, assess teamwork and resulting patient care outcomes, and also engage staff in problem solving about care issues, organizational decisions, and new initiatives that affect them. Management must be allowed to delegate tasks to others so that leadership behaviors as perceived by RNs as important to them can be maintained by the nurse manager (Schmalenberg \& Kramer, 2009).

\section{Conclusion}

The purpose of this study was to identify RN perceptions of their nurse manager behaviors that influenced the RNs' job satisfaction. In addition to learning about the RNs expectations of their nurse manager, the study also revealed a disconnection between what the RNs perceived the managers doing in their role and how it related to their daily work. This disconnect may demonstrate a lack of understanding of the manager's role by staff RNs, as well as reflect the difficulty for managers in fulfilling both dimensions of the leadership role (task and relationships with staff) due to the complexity and demands required in healthcare environments. Because the nurses believed increased visibility should be an expectation of the nurse manager, the level of job satisfaction for the RNs may decrease, especially during busy times if the nurse manager is not there to assist with issues and problem solving on the unit. This study provided findings important to staff nurses, nurse managers and administration. There is a need for administrator support for nurse manager's ability to spend more time on the unit with RNs to attend to direct care provider relationships and team building through communication with staff is a recommended approach for decreasing the disconnection between RNs and nurse managers. 


\section{R. A. FEATHER, P. R. EBRIGHT}

\section{REFERENCES}

Aiken, L., Clarke, S., Sloane, D., Sochalski, J., Busse, R., Clarke, H., \& Shamian, J. (2001). Nurses' reports on hospital care in five countries. Health Affairs, 20, 43-53. doi:10.1377/hlthaff.20.3.43

American Nurses Association (2008). ANA's health system reform agenda. http://www.nursingworld.org

Force, M. (2005). The relationship between effective nurse managers and nursing retention. Journal of Nursing Administration, 35, 336341.

Gormley, D. (2011). Are we on the same page? Staff nurse and manager perceptions of work environment, quality of care and anticipated nurse turnover. Journal of Nursing Management, 19, 33-40.

Herrin, D., \& Spears, P. (2007). Using nurse leader development to improve nurse retention and patient outcomes. Nursing Administration Quarterly, 31, 231-243. doi:10.1097/01.NAQ.0000278937.49491.34

Hersey, P., \& Blanchard, K. (1977). Management and organizational behavior. Englewood Cliffs, NJ: Prentice-Hall.

Kramer, M., Maguire, P., Schmalenberg, C., Brewer, B., Burke, R., Chmielewski, L., \& Waldo, M. (2007). Nurse manager support. What is it? Structures and practices that promote it. Nursing Administration Quarterly, 31, 325-340. doi:10.1097/01.NAQ.0000290430.34066.43

Kramer, M., Schmalenberg, C., \& Maguire, P. (2008). Essentials of a magnetic work environment. http://www.nursing2008.com

Morgan, D. (1998). Why should you use focus groups? In M. Flemming, \& D. Alexsen (Eds.), The focus group guidebook: Focus group kit 1 (pp. 9-16). Thousand Oaks, CA: Sage.

Sandelowski, M. (1995). Qualitative analysis: What it is and how to begin. Research in Nursing \& Health, 18, 371-375. doi:10.1002/nur.4770180411

Schmalenberg, C., \& Kramer, M. (2009). Nurse manager's support: How do staff nurses define it? Critical Care Nurse, 29, 61-69. doi:10.4037/ccn2009366

Sellgren, S., Ekvall, G., \& Tomson, G. (2006). Leadership styles in nursing management: Preferred and perceived. Journal of Nursing Management, 14, 348-355. doi:10.1111/j.1365-2934.2006.00624.X

Shirey, M., Ebright, P., \& McDaniel, A. (2013). Nurse manager cognitive decision-making a midst stress and work complexity. Journal of Nursing Management, 21, 17-30. doi:10.1111/j.1365-2834.2012.01380.x

Shirey, M., Ebright, P., \& McDaniel, A. (2008). Sleepless in America. Nurse managers cope with stress and complexity. The Journal of Nursing Administration, 38, 125-131. doi:10.1097/01.NNA.0000310722.35666.73

Shobbrook, P., \& Fenton, K. (2002). A strategy for improving nurse retention and recruitment levels. Professional Nursing, 17, 534-536.

Stuenkel, D., Nguyen, S., \& Cohen, J. (2007). Nurse perceptions of their work environment. Journal of Nursing Care Quarterly, 22, 337-342. doi:10.1097/01.NCQ.0000290415.50263.e6

Utriainen, K., \& Kyngas, H. (2009). Hospital nurses’ job satisfaction: A literature review. Journal of Nursing Management, 17, 1002-1010. 